\title{
On The Contribution of Interest Expense (Income) on Total Output
}

https://doi.org/10.1515/openec-2020-0112

Received Oct 19, 2020; accepted Mar 16, 2021

\begin{abstract}
A decrease in interest rate in traditional view of monetary policy transmission is linked to a lower cost of borrowing which eventually results into a greater spending in investment and a bigger GDP. However, a decrease in interest rate is also linked to a decrease in interest income which, in turn, affects the aggregate demand and total GDP. So far, no concerted effort has been made to investigate this positive inter-relation between interest income and GDP in the existing literature. Here in the first place we intuitively describe the inter-relation between interest income and output and then provide a micro-foundation of our intuitive reasoning in the context of a small endowment economy with finitely-lived identical households. Then we try to uncover the impact of nominal interest income on the macroeconomy using multiplier theory for a panel of some 04 (four) OECD countries. We define and calculate the corresponding multiplier values algebraically and then we empirically measure them using impulse response analysis under structural panel VAR framework. Large, consistent and positive values of the cumulative multipliers indicate a stable positive relationship between nominal interest income and output. Moreover, variance decomposition of GDP shows that a significant portion of the variance in GDP is attributed to interest income under VAR/VECM framework. Finally, we have shown how and where our analysis fits into the existing body of knowledge.
\end{abstract}

Keywords: nominal interest expense, nominal lending rate, domestic credit, GDP, economic multiplier, monetary policy transmission mechanism, banking

JEL: E43, E50, E52, G20, G21

\section{Introduction}

In the existing literature, nominal interest expense is usually considered as a cost of production (See for example, Hicks (1979)). When the interest rate rises so does the cost of production of the leveraged business concern which eventually shifts the aggregate supply curve upward resulting into a rise in general price level. A huge volume of literature has been dedicated to the investigation of the aforementioned effect of nominal interest expense on real economy. For example, Seelig (1974) investigates the relationship between interest rate and price hike using sectoral data and shows that interest rate would have to double for there to be a noteworthy increase in price. Barth and Ramey (2001) have shown that in many manufacturing concern, cost channel (nominal interest expense) is the primary mechanism for the transmission of monetary policy. They present aggregate and industry level evidences in favor of the existence of a cost channel of monetary policy transmission. Barth and Ramey (2001) also argue that this cost channel of monetary transmission has the ability to explain three empirical puzzles in monetary economics: The first puzzle being the degree of amplification observed by Bernenke and Gertler (1995): A small transitory movement in open market interest rate may have large persistent effect on output. The second puzzle in the list is the price puzzle first observed by Sims (1992) and last one being the comparative behavior of differential effect of monetary shocks on key

Ahmed Mehedi Nizam: The Central Bank of Bangladesh, 10 Arambagh, Motijheel, Dhaka- 1000, Bangladesh, E-mail: ahmed.mehedi@bb.org.bd, ahmed.mehedi.nizam@gmail.com 
macro-economic variables introduced by Barth and Ramey (2001). Gaiotti and Secchi (2006) observes the pricing behavior for some 2000 individual firms in Italy which are leveraged to some extent only to confirm the non-trivial existence of the cost channel of monetary transmission in micro level. Dedola and Lippi (2005) also find evidences in favor of the cost channel whereby industries with higher nominal interest expense are more likely to increase their relative price in the wake of a monetary contraction using empirical data of a sample of industries in five OECD countries. Meanwhile, Rabanal (2003) does not find any trace of the cost channel of monetary transmission in historical data of US and Euro area. However, Tillman (2006) argues that the cost channel can be effectively used to explain inflation under New Keynesian Phillips Curve framework.

All those are mentioned above tend to link nominal interest expense incurred by the borrower to price hike only overlooking the effect of nominal interest income earned by the banks and depositors on the aggregate spending. As the nominal interest expense incurred by the borrowers are distributed as nominal interest income to the depositors and banks, changing the nominal interest rate will not only effect the real economy from the supply side but it also has an equivalent impact on the demand side through nominal interest income channel. In this regard, another interesting area of research evolving around interest income and output among other things seeks to incorporate profit/utility maximizing banks, firms, government and households in a general equilibrium setup. In this type of analysis, both interest income and interest expense (with a lot of other things) are reasonably taken into account and banks, households, governments and firms all work diligently as intelligent agents each seeking to maximize its own unique objective function towards a general, market clearing equilibrium. See for example, Smets and Wouters (2007), Bernanke, Gertler and Gilchrist (1999), Christiano, Motto and Rostagno (2005), Gertler and Karadi (2011), Meh and Moran (2010) among others. In DSGE approach, a sequence of steps are followed: Writing down individual objective function for banks, firms, government and households, finding out the first order conditions regarding utility and profit maximization, deriving the steady state, linearizing the system around the steady state and solving the linearized system of equations. Thus the equilibrium relationship between interest income and output in these models are simulation based instead of being defined as a hard-coded algebraic identity and is presented as a complicated mass of a lot of related quantities lacking a precise representation facing the equilibrium. Here, we are more concerned to preserve the analytical structure of the problem and instead of resorting to simulation we try to quantify algebraically the effect of nominal interest income earned by the depositors and banks on total output considering the fact that the nominal interest income earned by the parties is successively invested into the economy resulting into a series of consumptions. Thus changing the nominal interest expense (resulting into a change in nominal interest income) is said to have a manifold effect on the economy: A unit change in nominal interest expense results into an other than unit change in total output.

Moreover, a huge volume of literature has been dedicated to the investigation of the inter-relation between interest rate and economic growth and the results of the studies are by and large inconclusive in nature. Some studies have reported limited or no effect of monetary policy variables like interest rate on output (neutrality of money) (see for example, Milani and Treadwell (2012), Kamaan (2014), Montiel (2012), Lashkary and Kashani (2011) among others) while others report significant implication of monetary policy variables (i.e., interest rate, money supply) on output (see Davoodi et al (2013), Onyeiwu (2012), Havi and Enu (2014), Vinayagathasan (2013), Kareem et al (2013)). To clutter things even more, some studies have reported mixed results regarding whether and to what extent monetary policy variables, i.e., interest rate can influence output (see Coibion (2011) for example). To us, the discrepancies and non-consensus in the empirical literature outlined above stem from the fact that interest rate alone cannot influence GDP much as long as it does not receive some sort of affirmation from the corresponding credit portfolio. When the interest rate rises on the backdrop of a monetary contraction then what happens to GDP still remains unclear and it depends heavily upon the responsiveness of the credit portfolio to the rise in interest rate. If the credit portfolio decreases significantly due to the rise in interest rate (as anticipated by the theory), then economy-wise interest income/expense decreases and so does the GDP. But, however, if the credit portfolio does not shrink accordingly due to changes in interest rate then the total interest income/expense may not decrease and GDP is left unaltered contrary to the existing monetary theory. The same is also true for monetary expansion brought about by the central bank in order to rescue the economy from the deep down. When the central bank decreases the interest rate 
by increasing money supply with a view to boost up the economy then its endeavor to rejuvenate the economy may succeed or fail. Whether it is successful or not, tends to depend upon the responsiveness of the credit portfolio to changes in interest rate. If the credit portfolio increases substantially due to the reduction in interest rate, then the total interest income/expense will rise and so does the GDP. But, if the credit portfolio does not respond much to the reduction in interest rate, then the total interest income/expense may not increase resulting into a mostly unaltered GDP and the monetary mechanism to reinstate the economy from economic bust fails. Here, we argue that whether monetary policy is effective in bringing about a real change in the economy depends heavily on the responsiveness of the credit portfolio to changes in policy variables. In this study, we resort to quantify the elasticities of the credit portfolio with respect to changes in policy variables, i.e., interest rate that are required for the monetary variables to have some real impacts on the economy.

The rest of the paper is organized as follows: Section 2 attempts to quantify the overall impact of nominal interest income on total output by introducing the concept of multipliers. Section 3 provides a microfoundation for the intuitive arguments presented in Section 2 in the context of a simplistic endowment economy with finitely lived households. Section 4 defines two different kinds of multiplier namely, cumulative and instantaneous multiplier. Section 5 provides the methodology used to calculate the multiplier values described in Section 4. Section 6 presents the results of empirical estimation of the multiplier values. Section 7 discusses how our analysis fits into the existing body of knowledge. Finally, Section 8 makes some concluding remarks.

\section{Contribution of Nominal Interest Expense on Total Output}

Before we proceed a few preliminary definitions are on the way.

- Average propensity to consume: Average propensity to consume of an entity is defined as the fraction of its total income spent in consumption. For a country as a whole, it can be calculated by dividing its total annual consumption expenditure (including both government and private consumption) by any of the measures of its national income and here we prefer GDP as a proxy to national income. Average propensity to consume is supposed to have a positive relationship with the impact of interest income on the total output. When average propensity to consume is found to be higher then the impact of nominal interest income on the macroeconomy is supposed to be much more pronounced as the entities receiving interest income tend to spend a significant portion of it in consumption which induces further consumptions.

- Average tax rate: Average tax rate is defined as the fraction of total income of an entity that is paid to the government as tax revenue. For an economy as a whole it can be calculated by dividing the total tax revenue collected by the government in a fiscal year by its Gross Domestic Product (GDP) in the same year. Higher the average tax rate lower will be the consumers' disposable income which implies lower level of private consumption going on inside the economy. Tax rate offers substantial friction against the chain of successive consumptions that are initiated by the initial interest income received by the depositors. When the average tax rate is set to a lower value then the impact of interest income will be much more pronounced as compared to the regime of higher average tax rate.

- Average propensity to import: Average propensity to import of an entity attempts to measure its tendency to purchase imported goods and services and can be estimated by dividing its total import by its total income in a given year. For a country as a whole average propensity to import can be calculated by dividing its total annual import by its Gross Domestic Product (GDP) in a particular year. If the depositors prefer foreign goods and services to local one then the impact of interest income on total output may become negative (as only net export contributes to output). A higher value of average of propensity to import signifies that a significant portion of interest income will be spent on purchasing imported goods and services which could alternatively be spent on purchasing locally produced goods and services.

- Velocity of money: Number of times money changes hands in a given year is known as the velocity of money. Other things remaining unchanged, when the velocity of money increases the contribution of interest income on the macroeconomy will be more felt. Every time money changes hands it indicates a 
financial transaction has taken place which may (or may not) add to the GDP of the country. For example, when money is used in purchasing locally produced consumer goods it adds to the country's GDP. However, when it is used to purchase a piece of land for example it does not contribute to the GDP.

To begin our analysis, let us assume that $L$ be the total amount of domestic credit in an economy. Let us also assume that the whole credit portfolio be segmented into $n$ parts depending upon the interest rate and $w_{i}, 0<w_{i} \leq 1, \forall i, 1 \leq i \leq n$ be the portion of credit with lending rate $l_{i}$. Then the weighted average lending rate of the total credit portfolio is given by the following construct:

$$
l=\sum_{i=1}^{n} w_{i} \times l_{i}
$$

Then the nominal interest expense incurred by the borrowers is given by:

$$
l \times L
$$

Above interest expense will be distributed to the depositors and financial intermidiaries as interest income and to government as taxes. If the Average Tax Rate of the economy as a whole is given by ATR then amount of disposable interest income of the entities receiving the nominal interest on deposit will be given by:

$$
(1-A T R) \times l \times L
$$

A part of this disposable income will be spent in consumption while another part will be saved. If the Average Propensity to Consume of the economy is given by APC then the amount spent in consumption will be given by:

$$
A P C \times(1-A T R) \times l \times L
$$

A part of the above spending is made to purchase locally produced goods and services while the rest will be spent to procure imported utilities. Thus, if the Average Propensity to Import of the economy is given by API then the amount spent in locally produced goods and services will be given by:

$$
\begin{gathered}
A P C \times(1-A T R) \times l \times L-A P I \times l \times L \\
=[A P C \times(1-A T R)-A P I] \times l \times L
\end{gathered}
$$

Let, the quantity $[A P C \times(1-A T R)-A P I]$ be given by $c$. Then the above quantity turns out to be:

$$
c \times l \times L
$$

The aforementioned spending in locally produced goods and services will be received by the local manufacturers and service providers who in turn spend a portion of it and save the rest and the process continues. Thus the initial nominal interest expense incurred by the borrower will trigger a series of subsequent consumptions in the economy. If the velocity of money is given by $v$ then we will have $(v-1)$ number of subsequent consumptions in a given year. Here, we assume $(v-1)$ number of subsequent consumptions instead of $v$ as money changes hand for the first time during the payment of nominal interest expense by the borrowers. Thus the total contribution $T C$ of the initial nominal interest expense $l \times L$ in a particular year will be given by the following sereis:

$$
\begin{gathered}
T C=(l \times L)+(c \times l \times L)+\left(c^{2} \times l \times L\right)+\left(c^{3} \times l \times L\right)+\ldots \ldots . .+\left(c^{v-1} \times l \times L\right) \\
=\left(1+c+c^{2}+c^{3}+\ldots \ldots . .+c^{v-1}\right) \times l \times L \\
T C=\frac{1-c^{v}}{1-c} \times l \times L
\end{gathered}
$$




\section{Microfoundation}

Here we assume an endowment economy populated by some finitely-lived households who live for $n$ periods and continuously try to maximize their overall lifetime utility through consumption. The problem can be easily extended to the version of infinitely-lived households' optimization problem by arbitrarily increasing the value of $n$. Households receive periodic endowment of $Y_{i}$ at period $i, \forall_{1 \leq i \leq n}$. Depending upon the present endowment, past savings and anticipated future interest rate households choose their present consumption level with a long term view to maximize their overall lifetime utility. If the interest rate is anticipated to be high in the future then substitution effect may come into play: Households may choose to curtail their current consumption with a view to consume more in future. Let the market interest rate at period $i$ be given by $r_{i}, \forall_{1 \leq i \leq n}$. We proceed with further analysis based upon the following assumptions:

- Periodic endowment $Y_{i}$ and interest rate $r_{i}$ are exogenously determined and are functions of time.

- Households receive simple interest on their accumulated savings i.e., there is no interest on interest.

- Savings made during period $i$ is entitled to interest payment at the rate of $r_{i+k}$ at period $(i+k), \forall_{k \in N \cup\{0\}}$. In the above circumstances here we try to investigate the responsiveness of total output to changes in interest income. Our analysis is segregated into several sections. In the first section we determine the optimal consumption sequence with respect to households' life time budget constraint. In the next two segments we calculate the responsiveness of household consumption and savings with respect to changes in interest income. Finally, we combine the responsiveness of households' consumption and savings to changes in interest income in order to arrive at the overall responsiveness of output with respect to changes in interest income.

- Optimal Consumption Sequence: Here we assume that the households live for $n$ periods. So, at the end of their finite life time i.e., at period $n$ households need to consume all of its periodic endowment $Y_{n}$ received in period $n$, interest income $I_{n}$ on total savings up to period $n$ and accumulated savings with interest there on $S_{n-1}$ up to period $(n-1)$. Hence we have:

$$
\begin{aligned}
C_{n} & =Y_{n}+I_{n}+S_{n-1} \\
& =Y_{n}+r_{n} \times \sum_{i=1}^{n}\left(Y_{i}-C_{i}\right)+\sum_{i=1}^{n-1}\left(Y_{i}-C_{i}\right) \times\left(1+\sum_{j=i}^{n-1} r_{j}\right)
\end{aligned}
$$

Rearranging the terms yields the households' life time budget constraint:

$$
\sum_{i=1}^{n} C_{i} \times\left(1+\sum_{j=i}^{n} r_{j}\right)=\sum_{i=1}^{n} Y_{i} \times\left(1+\sum_{j=i}^{n} r_{j}\right)
$$

Let us now assume that the households' life time utility function be given by the following:

$$
U(C)=\sum_{i=1}^{n} \beta^{i-1} \times \frac{C_{i}^{1-\sigma}}{1-\sigma}
$$

where $\beta$ is the discounting factor and $\sigma$ is the coefficient of Constant Relative Risk Aversion (CRRA). So, the households' optimization problem takes the following form:

$$
\begin{gathered}
\operatorname{Max} \sum_{i=1}^{n} \beta^{i-1} \times \frac{C_{i}^{1-\sigma}}{1-\sigma} \\
\text { S.T. } \sum_{i=1}^{n} C_{i} \times\left(1+\sum_{j=i}^{n} r_{j}\right)-\sum_{i=1}^{n} Y_{i} \times\left(1+\sum_{j=i}^{n} r_{j}\right)=0
\end{gathered}
$$

Taking the Lagrangian of the above maximization problem we get:

$$
L=\sum_{i=1}^{n} \beta^{i-1} \times \frac{C_{i}^{1-\sigma}}{1-\sigma}-\lambda \times\left[\sum_{i=1}^{n} C_{i} \times\left(1+\sum_{j=i}^{n} r_{j}\right)-\sum_{i=1}^{n} Y_{i} \times\left(1+\sum_{j=i}^{n} r_{j}\right)\right]
$$


Now we take the first partial derivative of the above Lagrangian with respect to $C_{i}$ and set it to zero as first order optimality condition. After doing so we get:

$$
C_{i}=\lambda^{-\frac{1}{\sigma}} \times\left[\frac{1+\sum_{j=i}^{n} r_{j}}{\beta^{i-1}}\right]^{-\frac{1}{\sigma}}
$$

Now we take the first partial derivative of the Lagrangian with respect to $\lambda$ and set it to zero as another first order condition. What we get here is essentially the households' life time budget constraint given by Equation: 2. Now substituting the value of $C_{i}$ from Equation: 3 into the budget constraint yields the following expression for $\lambda$ :

$$
\lambda=\left[\frac{\sum_{i=1}^{n} Y_{i} \times\left(1+\sum_{j=i}^{n} r_{j}\right)}{\beta^{\frac{i-1}{\sigma}} \times \sum_{i=1}^{n}\left[1+\sum_{j=i}^{n} r_{j}\right]^{\frac{\sigma-1}{\sigma}}}\right]^{-\sigma}
$$

Substituting the value of $\lambda$ from Equation: 4 into Equation: 3 we get a precise representation of $C_{i}$ in terms of the two endogenous of the system $Y_{i}, r_{i}$ and the system parameter $\sigma$ :

$$
C_{i}=\frac{\left(1+\sum_{j=i}^{n} r_{j}\right)^{-\frac{1}{\sigma}} \times \sum_{i=1}^{n} Y_{i} \times\left(1+\sum_{j=i}^{n} r_{j}\right)}{\sum_{i=1}^{n}\left(1+\sum_{j=i}^{n} r_{j}\right)^{\frac{\sigma-1}{\sigma}}}
$$

- Responsiveness of Household Consumption to Changes in Interest Income: Once we have a precise algebraic representation for optimal consumption sequence $C_{i}$ we can now calculate the rate of change in optimal consumption with respect to periodic endowment and interest rate given by $\frac{\partial C_{i}}{\partial Y_{i}}$ and $\frac{\partial C_{i}}{\partial r_{i}}$ respectively.

Now, at any arbitrary period $p, 1 \leq p \leq n$ the value of consumption $C_{p}$ is given by:

$$
C_{p}=\frac{\left(1+\sum_{j=p}^{n} r_{j}\right)^{-\frac{1}{\sigma}} \times \sum_{i=1}^{n} Y_{i} \times\left(1+\sum_{j=i}^{n} r_{j}\right)}{\sum_{i=1}^{n}\left(1+\sum_{j=i}^{n} r_{j}\right)^{\frac{\sigma-1}{\sigma}}}
$$

Differentiating $C_{p}$ with respect to $Y_{k}, \forall_{k \in N, k \leq n}$ we get the following:

$$
\frac{\partial C_{p}}{\partial Y_{k}}=\frac{\left(1+\sum_{j=p}^{n} r_{j}\right)^{-\frac{1}{\sigma}} \times\left(1+\sum_{j=k}^{n} r_{j}\right)}{\sum_{i=1}^{n}\left(1+\sum_{j=i}^{n} r_{j}\right)^{\frac{\sigma-1}{\sigma}}}
$$

Other things remaining unchanged (by other thing here we mean interest rate $r_{i}$ and system parameter $\sigma$ ), the above expression represents the instantaneous rate of change in consusmption in response to change in periodic endowment.

Now, we are going to differentiate $C_{p}$ with respect to interest rate $r_{k}$ at any arbitrary period $k$ and using quotient rule of differentiation we get the following expression for $\frac{\partial C_{p}}{\partial r_{k}}$ :

$$
\frac{\partial C_{p}}{\partial r_{k}}=\frac{D \times \frac{\partial N}{\partial r_{k}}-N \times \frac{\partial D}{\partial r_{k}}}{D^{2}}
$$

where $N$ and $D$ represent the numerator and denominator of $C_{p}$ given by Equation: 6 . Now from Equation: 6 we can see that:

$$
\begin{aligned}
\frac{\partial D}{\partial r_{k}} & =\frac{\partial}{\partial r_{k}} \sum_{i=1}^{n}\left[\left(1+\sum_{j=i}^{n} r_{j}\right)\right]^{\frac{\sigma-1}{\sigma}} \\
& =\sum_{i=1}^{n} \frac{\partial}{\partial r_{k}}\left[\left(1+\sum_{j=i}^{n} r_{j}\right)\right]^{\frac{\sigma-1}{\sigma}}
\end{aligned}
$$

The above expression represents the sum of the differentiation of some $n$ terms of the series $\left[1+\sum_{j=i}^{n} r_{j}\right]^{\frac{\sigma-1}{\sigma}}$ with respect to $r_{k}$. However, the terms of the series where the index $i>k$ do not have 
an $r_{k}$ term and hence their differentiation with respect to $r_{k}$ is zero. Only the terms where the value of the index $i \leq k$ give non-zero results when differentiated with respect to $r_{k}$. So, we get the following expression for $\frac{\partial D}{\partial r_{k}}$ :

$$
\begin{aligned}
\frac{\partial D}{\partial r_{k}} & =\sum_{i=1}^{k} \frac{\partial}{\partial r_{k}}\left[\left(1+\sum_{j=i}^{n} r_{j}\right)\right]^{\frac{\sigma-1}{\sigma}} \\
& =\sum_{i=1}^{k} \frac{\sigma-1}{\sigma} \times\left(1+\sum_{j=i}^{n} r_{j}\right)^{-\frac{1}{\sigma}}
\end{aligned}
$$

So, we have got:

$$
\frac{\partial D}{\partial r_{k}}=\frac{\sigma-1}{\sigma} \times \sum_{i=1}^{k}\left(1+\sum_{j=i}^{n} r_{j}\right)^{-\frac{1}{\sigma}}
$$

Now from Equation: 6 we can see that

$$
N=\left[1+\sum_{j=p}^{n} r_{j}\right]^{-\frac{1}{\sigma}} \times \sum_{i=1}^{n} Y_{i} \times\left[1+\sum_{j=i}^{n} r_{j}\right]
$$

So, differentiating $N$ with respect to $r_{k}$ yields:

$$
\frac{\partial N}{\partial r_{k}}=A \times \frac{\partial B}{\partial r_{k}}+B \times \frac{\partial A}{\partial r_{k}}
$$

where

$$
\begin{gathered}
A=\left[1+\sum_{j=p}^{n} r_{j}\right]^{-\frac{1}{\sigma}} \\
B=\sum_{i=1}^{n} Y_{i} \times\left[1+\sum_{j=i}^{n} r_{j}\right]
\end{gathered}
$$

Now,

$$
\frac{\partial A}{\partial r_{k}}=\frac{\partial}{\partial r_{k}}\left[1+\sum_{j=p}^{n} r_{j}\right]^{-\frac{1}{\sigma}}
$$

When $p>k$ then $\left[1+\sum_{j=p}^{n} r_{j}\right]^{-\frac{1}{\sigma}}$ does not contain an $r_{k}$ term and differentiating it with respect to $r_{k}$ entails zero. The non-zero results are only obtained when $p \leq k$. So, when $p \leq k$ differentiation with respect to $r_{k}$ entails the following result:

$$
\frac{\partial A}{\partial r_{k}}=-\frac{1}{\sigma} \times\left[1+\sum_{j=p}^{n} r_{j}\right]^{-\frac{1+\sigma}{\sigma}}
$$

Now differentiating $B$ with respect to $r_{k}$ yields:

$$
\begin{aligned}
\frac{\partial B}{\partial r_{k}} & =\frac{\partial}{\partial r_{k}}\left[\sum_{i=1}^{n} Y_{i} \times\left[1+\sum_{j=i}^{n} r_{j}\right]\right] \\
& =\sum_{i=1}^{n} \frac{\partial}{\partial r_{k}}\left[Y_{i} \times\left[1+\sum_{j=i}^{n} r_{j}\right]\right]
\end{aligned}
$$


The expression represents the summation of differentiation of some $n$ terms of the series $Y_{i} \times\left[1+\sum_{j=i}^{n} r_{j}\right]$ and each term of the series is indexed by $i$. The terms of the above series with index $i>k$ do not contain any $r_{k}$ term and hence their differentiation with respect to $r_{k}$ entails zero. So, the other terms where the index $i \leq k$ contain an $r_{k}$ term and hence when differentiated with respect to $r_{k}$ yields non-zero results. In this circumstance the expression above turns out to be:

$$
\begin{aligned}
\frac{\partial B}{\partial r_{k}} & =\sum_{i=1}^{k} \frac{\partial}{\partial r_{k}}\left[Y_{i} \times\left[1+\sum_{j=i}^{n} r_{j}\right]\right] \\
& =\sum_{i=1}^{k} Y_{i}
\end{aligned}
$$

In the derivation of the above expression we use the fact that the periodic endowment $Y_{i}$ at any arbitrary period $i$ does not tend to depend upon interest rate $r_{k}$ at any arbitrary period $k$. Rather both $Y_{i}$ and $r_{k}$ $(\forall 1 \leq i, k \leq n)$ are exogenously determined and are independent of each other.

So,

$$
\frac{\partial B}{\partial r_{k}}=\sum_{i=1}^{k} Y_{i}
$$

Substituting the value of $\frac{\partial A}{\partial r_{k}}$ and $\frac{\partial B}{\partial r_{k}}$ from Equation: 11 and 12 into Equation: 10 we can get the value of $\frac{\partial N}{\partial r_{k}}$. Once we get the value of $\frac{\partial N}{\partial r_{k}}$ we substitute it into Equation: 8. Moreover, the value of $\frac{\partial D}{\partial r_{k}}$ from Equation: 9 is substituted into Equation: 8 in order to get the final value of $\frac{\partial C_{p}}{\partial r_{k}}$.

We now determine the partial derivative of interest income at period $p$ with respect to periodic endowment $\left(Y_{k}\right)$ and interest rate $\left(r_{k}\right)$ at any arbitrary period $k, 1 \leq k \leq n$. Let us now recall the definition of interest income $I_{p}$ at period $p$ :

$$
I_{p}=r_{p} \times \sum_{j=1}^{p}\left(Y_{j}-C_{j}\right)
$$

Differentiating both sides with respect to $Y_{k}$ yields the following:

$$
\frac{\partial I_{p}}{\partial Y_{k}}=r_{p} \times \sum_{j=1}^{p} \frac{\partial Y_{j}}{\partial Y_{k}}-r_{p} \times \sum_{j=1}^{p} \frac{\partial C_{j}}{\partial Y_{k}}
$$

When we differentiate the above expression with respect to $Y_{k}$ we take $r_{p}$ as constant. This is due to the fact that periodic endowment and interest rate are assumed to be exogenously determined and are independent of each other.

Now, the first segment of the right hand side indicates the summation of differentiation of the first $p$ endowments with respect to endowment at time $k$. As the endowments in different time periods are independent of one another differentiating one with respect to other returns zero. Hence, if $k>p$ then the differentiation with respect to $Y_{k}$ of all the terms of the aforementioned series entails zero and we get:

$$
\frac{\partial I_{p}}{\partial Y_{k}}=-r_{p} \times \sum_{j=1}^{p} \frac{\partial C_{j}}{\partial Y_{k}}
$$

Substituting the valuees of $\frac{\partial C_{j}}{\partial Y_{k}}, 1 \leq j \leq p$ from Equation: 7 we get an algebraic representation for $\frac{\partial I_{p}}{\partial Y_{k}}$. On the other hand if $k \leq p$ we get the following representation for $\frac{\partial I_{p}}{\partial Y_{k}}$.

$$
\frac{\partial I_{p}}{\partial Y_{k}}=r_{p}-r_{p} \times \sum_{j=1}^{p} \frac{\partial C_{j}}{\partial Y_{k}}
$$

Substituting the valuees of $\frac{\partial C_{j}}{\partial Y_{k}}, 1 \leq j \leq p$ from Equation: 7 we get an algebraic representation for $\frac{\partial I_{p}}{\partial Y_{k}}$ when $k \leq p$. 
In the next step we will calculate the partial derivative of interest income $I_{p}$ at period $p$ with respect to interest rate $r_{k}$ at period $k$. Differentiating Equation: 13 with respect to $r_{k}$ we get the following:

$$
\frac{\partial I_{p}}{\partial r_{k}}=\frac{\partial}{\partial r_{k}}\left[r_{p} \times \sum_{j=1}^{p}\left(Y_{j}-C_{j}\right)\right]
$$

As $Y$ and $r$ are two independent variables derivative of $Y$ with respect to $r$ is zero irrespective of the value of the index. Applying this fact on the above equation yields:

$$
\begin{aligned}
\frac{\partial I_{p}}{\partial r_{k}} & =-\frac{\partial}{\partial r_{k}} \sum_{j=1}^{p}\left[r_{p} \times C_{j}\right] \\
& =-\sum_{j=1}^{p} \frac{\partial}{\partial r_{k}}\left[r_{p} \times C_{j}\right]
\end{aligned}
$$

When we differentiate the above expression with respect to $r_{k}$ we can take $r_{p}$ as constant as long as $p \neq k$ using the fact that the interest rates at different time periods are exogenously determined and are independent of each other. In that case the above expression turns out to be:

$$
\frac{\partial I_{p}}{\partial r_{k}}=-r_{p} \times \sum_{j=1}^{p} \frac{\partial C_{j}}{\partial r_{k}}
$$

Substituting the values of $\frac{\partial C_{j}}{\partial r_{k}}, \forall_{1 \leq j \leq p}$ from Equation: 8 we can get an algebraic representation for $\frac{\partial I_{p}}{\partial r_{k}}$. On the other hand if $p=k$ then we have the following expression for $\frac{\partial I_{p}}{\partial r_{k}}$.

$$
\begin{aligned}
\frac{\partial I_{p}}{\partial r_{k}} & =-\frac{\partial}{\partial r_{k}} \sum_{j=1}^{k}\left(r_{k} \times C_{j}\right) \\
& =-\sum_{j=1}^{k} \frac{\partial}{\partial r_{k}}\left(r_{k} \times C_{j}\right) \\
& =-\sum_{j=1}^{k}\left[C_{j}+r_{k} \times \frac{\partial C_{j}}{\partial r_{k}}\right]
\end{aligned}
$$

So we have:

$$
\frac{\partial I_{p}}{\partial r_{k}}=-\sum_{j=1}^{k}\left[C_{j}+r_{k} \times \frac{\partial C_{j}}{\partial r_{k}}\right]
$$

Substituting the values of $C_{j}$ and $\frac{\partial C_{j}}{\partial r_{k}}, \forall_{1 \leq j \leq k}$ from Equation: 5 and 8 respectively we can precisely calculate $\frac{\partial I_{p}}{\partial r_{k}}$.

In this step we will calculate the partial derivative of interest income at period $p$ with respect to consumption. Here, we again recall from Equation: 13 that interest income is a function of endowment, interest rate and consumption. Now taking partial derivative of Equation: 13 with respect to $C_{p}$ yields:

$$
\begin{aligned}
\frac{\partial I_{p}}{\partial C_{p}} & =r_{p} \times \sum_{j=1}^{p} \frac{\partial\left(Y_{i}-C_{i}\right)}{\partial C_{p}} \\
& =-r_{p} \times \sum_{j=1}^{p} \frac{\partial C_{i}}{\partial C_{p}}
\end{aligned}
$$

In the derivation of the above expression we employ the fact that the periodic endowment $Y_{i}$ at any arbitrary period $i, 1 \leq i \leq n$ is exogenously determined and depends upon time only. Hence, differentiating periodic endowment with respect to consumption yields zero irrespective of the value of the index $i$, i.e., 
it is true for all $i \in N, i \leq n$. Moreover, as consumption in the earlier period can not depend upon consumption at some later time differentiating $C_{i}, \forall_{1 \leq i \leq(p-1)}$ with respect to $C_{p}$ yields zero and differentiating $C_{p}$ with respect to $C_{p}$ itself entails one. Exploiting the above fact we get:

$$
\frac{\partial I_{p}}{\partial C_{p}}=-r_{p}
$$

Let us now rewrite Equation: 13 in the following manner:

$$
C_{p}=\sum_{i=1}^{p} Y_{i}-\frac{I_{p}}{r_{p}}-\sum_{i=1}^{p-1} C_{i}
$$

Here we note that periodic endowment $Y_{i}, \forall_{1 \leq i \leq n}$ is an independent variable and is determined exogenously. Hence differentiating $Y_{i}, \forall_{1 \leq i \leq n}$ with respect to interest income $I_{p}$ entails zero. Moreover, interest income $I_{p}$ received by the households during period $p$ can influence consumption $C_{p}$ as it comes as an inflow for the households at period $p$. As $I_{p}$ influences $C_{p}$ it also has an impact on households' gross savings during period $p$. As gross savings at period $p$ are influenced by the interest income at period $p$ all consumptions subsequent to period $p$ are also effected by interest income at period $p$. This realization stems from the fact that the gross savings made at period $p$ will be available for consumptions for all subsequent periods. However, $I_{p}$ does not have any influence on consumption in periods earlier than $p$. This is due to the trivial fact that interest income can only contribute to consumptions (and hence savings) only after it is realized/earned. Before the interest income is earned/realized it can not influence consumption (and savings as well). Employing the above facts and differentiating both sides of the above equation with respect to $I_{p}$ yields the following:

$$
\frac{\partial C_{p}}{\partial I_{p}}=-\frac{1}{r_{p}}
$$

Now that we have algebraically estimated $\frac{\partial C_{p}}{\partial Y_{k}}$, $\frac{\partial C_{p}}{\partial r_{k}}$, $\frac{\partial I_{p}}{\partial Y_{k}}$, $\frac{\partial I_{p}}{\partial r_{k}}$ and $\frac{\partial I_{p}}{\partial C_{p}}$ by Equations: 7, 8, 14, 15, 16, 17 and 18 we are now in the position to estimate the instantaneous rate of change in consumption with respect to interest income. Let us now recall from Equation: 5 and 13 that consumption is a function of $Y$ and $r$ [i.e., $\mathrm{C}(\mathrm{Y}, \mathrm{r})$ ] while interest income is a function of $Y, r$ and $C$ [i.e., $\mathrm{I}(\mathrm{Y}, \mathrm{r}, \mathrm{C})$ ]. Moreover, we have asssumed here that $Y$ and $r$ are two exogenous variables which depend upon time (t). Hence taking the total derivative of consumption $C_{p}$ and interest income $I_{p}$ with respect to time we get:

$$
\begin{gathered}
\frac{d C_{p}}{d t}=\frac{\partial C_{p}}{\partial Y_{p}} \frac{d Y_{p}}{d t}+\frac{\partial C_{p}}{\partial r_{p}} \frac{d r_{p}}{d t} \\
\frac{d I_{p}}{d t}=\frac{\partial I_{p}}{\partial C_{p}}\left[\frac{\partial C_{p}}{\partial Y_{p}} \frac{d Y_{p}}{d t}+\frac{\partial C_{p}}{\partial r_{p}} \frac{d r_{p}}{d t}\right]+\frac{\partial I_{p}}{\partial Y_{p}} \frac{d Y_{p}}{d t}+\frac{\partial I_{p}}{\partial r_{p}} \frac{d r_{p}}{d t}
\end{gathered}
$$

From the above equations we get:

$$
\frac{\frac{d C_{p}}{d t}}{\frac{d I_{p}}{d t}}=\frac{\frac{\partial C_{p}}{\partial Y_{p}} \frac{d Y_{p}}{d t}+\frac{\partial C_{p}}{\partial r_{p}} \frac{d r_{p}}{d t}}{\frac{\partial I_{p}}{\partial C_{p}}\left[\frac{\partial C_{p}}{\partial Y_{p}} \frac{d Y_{p}}{d t}+\frac{\partial C_{p}}{\partial r_{p}} \frac{d r_{p}}{d t}\right]+\frac{\partial I_{p}}{\partial Y_{p}} \frac{d Y_{p}}{d t}+\frac{\partial I_{p}}{\partial r_{p}} \frac{d r_{p}}{d t}}
$$

Rearranging the above expression we get:

$$
\frac{d C_{p}}{d I_{p}}=\frac{\frac{\partial C_{p}}{\partial Y_{p}} \frac{d Y_{p}}{d t}+\frac{\partial C_{p}}{\partial r_{p}} \frac{d r_{p}}{d t}}{\frac{\partial I_{p}}{\partial C_{p}}\left[\frac{\partial C_{p}}{\partial Y_{p}} \frac{d Y_{p}}{d t}+\frac{\partial C_{p}}{\partial r_{p}} \frac{d r_{p}}{d t}\right]+\frac{\partial I_{p}}{\partial Y_{p}} \frac{d Y_{p}}{d t}+\frac{\partial I_{p}}{\partial r_{p}} \frac{d r_{p}}{d t}}
$$

Equation: 22 shows the instantaneous rate of change of consumption at period $p$ with respect to change in interest income at period $p$. Values of $\frac{\partial C_{p}}{\partial Y_{p}}, \frac{\partial C_{p}}{\partial r_{p}}, \frac{\partial I_{p}}{\partial Y_{p}}, \frac{\partial I_{p}}{\partial r_{p}}$ and $\frac{\partial I_{p}}{\partial C_{p}}$ can be calculated by using Equations: $7,8,14,15,16,17$ and 18. On the other hand periodic endowment $Y_{p}$ and interest rate $r_{p}$ are exogenous variables and hence their rate of change with respect to time are also exogenous to the system and are given before hand. As all the values are known we can calculate the instantaneous responsiveness of household consumption with respect to change in interest income using Equation: 22. 


\section{- Responsiveness of Household Savings to Changes in Interest Income:}

In the next step we will investigate how gross savings made by the households at period $p$ respond to changes in interest income at period $p$. We start our quest by recalling the definition of total income (M) that are at disposal of the households at period $p$ :

$$
M=Y_{p}+I_{p}+S_{p-1}
$$

The above expression shows that the total disposable income of the households at period $p$ is the summation of periodic endowmnent $\left(Y_{p}\right)$, interest income $\left(I_{p}\right)$ and accumulated savings with interest there on up to period $(p-1)$. A portion of the above income will be spent on consumption and the another portion is saved. If the consumption made during the period $p$ is given by $C_{p}$ then we have:

$$
C_{p}+S_{p}=Y_{p}+I_{p}+S_{p-1}
$$

$S_{p}$ represents households' accumulated savings with interest there on up to period $p$. Subtracting $S_{p-1}$ from $S_{p}$ we get the gross savings made by the households during period $p$ alone. Hence rewriting the above expression yields:

$$
G S_{p}=S_{p}-S_{p-1}=Y_{p}+I_{p}-C_{p}
$$

Differentiating both sides of the above equation with respect to $I_{p}$ we get:

$$
\frac{\partial G S_{p}}{\partial I_{p}}=\frac{\partial Y_{p}}{\partial I_{p}}+1-\frac{\partial C_{p}}{\partial I_{p}}
$$

As periodic endowment $Y_{p}$ at period $p$ is exogenously determined its derivative with respect to $I_{p}$ yields zero. Hence, the above equation turns out to be:

$$
\frac{\partial G S_{p}}{\partial I_{p}}=1-\frac{\partial C_{p}}{\partial I_{p}}
$$

Using Equation:19 we can effectively calculate the value of $\frac{\partial C_{p}}{\partial I_{p}}$ which in turn enables us to calculate $\frac{\partial G S_{p}}{\partial I_{p}}$ analytically using Equation: 24.

Now differentiating Equation: 23 with respect to $Y_{p}$ yields the following:

$$
\frac{\partial G S_{p}}{\partial Y_{p}}=1+\frac{\partial I_{p}}{\partial Y_{p}}-\frac{\partial C_{p}}{\partial Y_{p}}
$$

As $\frac{\partial I_{p}}{\partial Y_{p}}$ and $\frac{\partial C_{p}}{\partial Y_{p}}$ can be calculated using Equation: 14 and 15 and Equation:7 respectively Equation:25 can be used to calculate $\frac{\partial G S_{p}}{\partial Y_{p}}$.

Now we will estimate the responsiveness of households' gross savings to change in consumption. To do so we differentiate both sides of Equation: 21 with respect to $C_{p}$. After doing so we get the following expression:

$$
\frac{\partial G S_{p}}{\partial C_{p}}=\frac{\partial Y_{p}}{\partial C_{p}}+\frac{\partial I_{p}}{\partial C_{p}}-1
$$

As we have already mentioned in our previous discussion that the periodic endowment $Y_{p}$ is exogenously determined and hance it does not tend to depend upon any other variables under consideration. Hence, differentiating $Y_{p}$ with respect to $C_{p}$ yields zero. So the above equation turns out to be:

$$
\frac{\partial G S_{p}}{\partial C_{p}}=\frac{\partial I_{p}}{\partial C_{p}}-1
$$

Thus we can calculate the value of $\frac{\partial G S_{p}}{\partial C_{p}}$ analytically using Equation: 26 after substituting the value of $\frac{\partial I_{p}}{\partial C_{p}}$ from Equation: 18.

From Equation: 23 it is evident that gross savings made by the households is a function of periodic endowment, interest income and consumption [i.e., GS(Y, I, C)]. Whereas endowment and interest income represents inflows of fund consumption represents fund outflow. As we have discussed previously periodic endowments received by the households are exogenously determined and is a function of time. 
Moreover, from Equation: 13 we can see that interest income is a function of consumption, endowment and interest rate [i.e., I(C, Y, r)]. On the other hand from Equation: 5 we can see that consumption is a function of periodic endowment and interest rate [i.e., $\mathrm{C}(\mathrm{Y}, \mathrm{r})]$. Considering the above facts and using chain rule of differentiation we get:

$$
\frac{d G S_{p}}{d t}=\frac{\partial G S_{p}}{\partial Y_{p}} \frac{d Y_{p}}{d t}+\frac{\partial G S_{p}}{\partial C_{p}}\left[\frac{\partial C_{p}}{\partial Y_{p}} \frac{d Y_{p}}{d t}+\frac{\partial C_{p}}{\partial r_{p}} \frac{d r_{p}}{d t}\right]+\frac{\partial G S_{p}}{\partial I_{p}}\left[\frac{\partial I_{p}}{\partial C_{p}}\left[\frac{\partial C_{p}}{\partial Y_{p}} \frac{d Y_{p}}{d t}+\frac{\partial C_{p}}{\partial r_{p}} \frac{d r_{p}}{d t}\right]+\frac{\partial I_{p}}{\partial Y_{p}} \frac{\partial Y_{p}}{d t}+\frac{\partial I_{p}}{\partial r_{p}} \frac{d r_{p}}{d t}\right]
$$

So, to calculate the total derivative of households' gross savings with respect to time i.e., $\frac{d G S_{p}}{d t}$ analytically we need the values of different partial derivatives including $\frac{\partial G S_{p}}{\partial Y_{p}}, \frac{\partial G S_{p}}{\partial C_{p}}, \frac{\partial C_{p}}{\partial Y_{p}}, \frac{\partial C_{p}}{\partial r_{p}}, \frac{\partial G S_{p}}{\partial I_{p}}, \frac{\partial I_{p}}{\partial C_{p}}, \frac{\partial I_{p}}{\partial Y_{p}}, \frac{\partial I_{p}}{\partial r_{p}}$ and these values are available from Equation: 25, 26, 7, 8, 24, 18, 14, 15, 16 and 17 respectively. Moreover, we also need the derivative $\frac{d Y_{p}}{d t}$ and $\frac{d r_{p}}{d t}$ which are determined exogenously and are given.

In the next step we divide the total derivative of households' gross savings with respect to time (Equation: 27) by the total derivative of interest income with respect to time (given by Equation: 21) and we get the following as a result:

$$
\frac{\frac{d G S_{p}}{d t}}{\frac{d I_{p}}{d t}}=\frac{\frac{\partial G S_{p}}{\partial Y_{p}} \frac{d Y_{p}}{d t}+\frac{\partial G S_{p}}{\partial C_{p}}\left[\frac{\partial C_{p}}{\partial Y_{p}} \frac{d Y_{p}}{d t}+\frac{\partial C_{p}}{\partial r_{p}} \frac{d r_{p}}{d t}\right]+\frac{\partial G S_{p}}{\partial I_{p}}\left[\frac{\partial I_{p}}{\partial C_{p}}\left[\frac{\partial C_{p}}{\partial Y_{p}} \frac{d Y_{p}}{d t}+\frac{\partial C_{p}}{\partial r_{p}} \frac{d r_{p}}{d t}\right]+\frac{\partial I_{p}}{\partial Y_{p}} \frac{\partial Y_{p}}{d t}+\frac{\partial I_{p}}{\partial r_{p}} \frac{d r_{p}}{d t}\right]}{\frac{\partial I_{p}}{\partial C_{p}}\left[\frac{\partial C_{p}}{\partial Y_{p}} \frac{d Y_{p}}{d t}+\frac{\partial C_{p}}{\partial r_{p}} \frac{d r_{p}}{d t}\right]+\frac{\partial I_{p}}{\partial Y_{p}} \frac{d Y_{p}}{d t}+\frac{\partial I_{p}}{\partial r_{p}} \frac{d r_{p}}{d t}}
$$

Rewriting the above equation we can get the total derivative of households' gross savings with respect to time:

$$
\frac{d G S_{p}}{d I_{p}}=\frac{\frac{\partial G S_{p}}{\partial Y_{p}} \frac{d Y_{p}}{d t}+\frac{\partial G S_{p}}{\partial C_{p}}\left[\frac{\partial C_{p}}{\partial Y_{p}} \frac{d Y_{p}}{d t}+\frac{\partial C_{p}}{\partial r_{p}} \frac{d r_{p}}{d t}\right]+\frac{\partial G S_{p}}{\partial I_{p}}\left[\frac{\partial I_{p}}{\partial C_{p}}\left[\frac{\partial C_{p}}{\partial Y_{p}} \frac{d Y_{p}}{d t}+\frac{\partial C_{p}}{\partial r_{p}} \frac{d r_{p}}{d t}\right]+\frac{\partial I_{p}}{\partial Y_{p}} \frac{\partial Y_{p}}{d t}+\frac{\partial I_{p}}{\partial r_{p}} \frac{d r_{p}}{d t}\right]}{\frac{\partial I_{p}}{\partial C_{p}}\left[\frac{\partial C_{p}}{\partial Y_{p}} \frac{d Y_{p}}{d t}+\frac{\partial C_{p}}{\partial r_{p}} \frac{d r_{p}}{d t}\right]+\frac{\partial I_{p}}{\partial Y_{p}} \frac{d Y_{p}}{d t}+\frac{\partial I_{p}}{\partial r_{p}} \frac{d r_{p}}{d t}}
$$

The above equation depicts the total derivative of households' gross savings with respect to interest income i.e., it shows how households' gross savings respond instantaneously to any change in interest income.

\section{- Responsiveness of output to changes in interest income}

In our representative economy output at a particular period is assumed to be the summation of households' consumption and gross savings. Gross savings are assumed to be parts of the total output because the savings made by the households are eventually invested by the firms. The behavior of the firms in this simiplistic economy is not modelled because doing so would irrevocably break the nice analytical structure of the problem and make us prone to extensive simulation to decipher any inter-relation between interest income and output. So in our representative economy:

$$
G D P_{p}=C_{p}+G S_{p}
$$

where $G D P_{p}, C_{p}$ and $G S_{p}$ are the output, consumption and savings at period $p$ in our representative economy. Differentiating both sides of the above equation with respect to interest income $I_{p}$ we get:

$$
\frac{d G D P_{p}}{d I_{p}}=\frac{d C_{p}}{d I_{p}}+\frac{d G S_{p}}{d I_{p}}
$$

Now the value of $\frac{d C_{p}}{d I_{p}}$ and $\frac{d G S_{p}}{d I_{p}}$ can be obtained from Equation: 22 and 28 respectively. If we substitute the value of $\frac{d C_{p}}{d I_{p}}$ and $\frac{d G S_{p}}{d I_{p}}$ into Equation: 29 then we will be able to obtain the total derivative of output with respect to interest income: The quantity thus calculated will show how output will respond instantaneously to any changes in interest income or in other words this is indeed our desired interest income multiplier.

\section{Different Kinds of Multipliers}

From equation: 1, it is evident that if we change nominal interest expense by one unit it will bring about a more than one unit change in output due to multiplier effect. The multiplier namely $\frac{1-c^{v}}{1-c}$ represents the 
change in nominal GDP brought about by an unit change in nominal interest expense. From now on, we call it as the nominal interest expense multiplier. Like the fiscal multipliers, we can define nominal interest expense multiplier both as impact and cumulative multipliers depending upon the forcasting horizon under consideration. For impact multiplier (IM), the forcasting horizon can be only one period long and it can be defined as follows:

$$
I M=\frac{\Delta G D P}{\Delta I E}
$$

where $\triangle G D P$ represents changes in GDP brought about by $\triangle I E$ change in interest expense. However, the change in nominal interest expense can have a pronounced effect on total output extending from the period the change is applied to several subsequent time periods ahead. And that is why we feel it necessary to define a cumulative version of the nominal interest expense multiplier:

$$
C M=\frac{\sum_{i=1}^{n}(1+d)^{-i} \Delta G D P_{i}}{\sum_{i=1}^{n}(1+d)^{-i} \Delta I E_{i}}
$$

where $n$ represents the forcasting horizon under consideration and $d$ is the discounting rate. Here $d$ is used to appropriately discount the future responses.

\section{Methodology}

- We begin our analysis by testing for unit roots in the time series data of nominal interest income and GDP using different types of panel unit root testing. Tests used in our analysis include Levin-Lin-Chu test, Breitung t-statistic test, Im, Pesaran and Shin W-statistic test, ADF-Fisher Chi-square test and PP-Fisher Chi-square test. The longitudinal data are at first converted into their natural logarithmic form before feeding into unit root tests in order to remove heteroskedasticity.

- We then build an unrestricted VAR model using each of the variables in level and determine the lag length that minimizes the majority of information criteria including LR, FPE, AIC, SC and HQ. The dynamic stability of the selected VAR model are then tested by plotting all the inverse roots of the AR-characteristic polynomial. If all the inverse roots lie within the unit circle then the selected VAR model is said to be dynamically stable. If the VAR model is found unstable then we increase the lag length by one and repeat the whole procedure of checking dynamic stability. The process continues until and unless we find a VAR model that is dynamically stable.

- Now we know the specific order of integration of our longitudinal data. As all the longitudinal data series are integrated of order 01 (one) (we report it later in the data section), we then check for cointegration amongst them using Pedroni (Engle-Granger) test and Kao test for cointegration. Pedroni (Engle-Granger) tests are carried out using three different parameter settings: individual intercept, intercept and trend and finally no intercept and no trend version of the test. For each of the three settings we report a total of 11 (eleven) different statistics' values which includes normal and weighted version of Panel v-Statistic, Panel rho-Statistic, Panel PP-Statistic, Panel ADF-Statistic and three more statistics namely Group rho-Statistic, Group PP-Statistic and Group ADF-Statistic. Alongside the statistics' values corresponding p-values are also reported. The conclusions suggested by the majority of the 11 (eleven) different criteria are taken. In the next step we carry out Kao test using individual intercept (as Kao test does not come up with the other two common variants namely individual intercept and individual trend version and no intercept, no trend version) and report the corresponding t-statistics along with the $\mathrm{p}$-value.

- If the variables are found to be cointegrated then we proceed to build a Vector Error Correction Model (VECM). VECM allows us to check for both short term and long term causal relationships amongst the cointegrating variables. In the first place, it provides us a cointegrating equation which embodies the long run relationship amongst the variables. Moreover, it provides us with an Error Correction Model (ECM) which allows to check for the short term causal relationships among the variables.

- After the VECM is constructed we provide one standard deviation Choleski shock in interest income and note down the responses of both GDP and interest income itself over subsequent time periods. To model 
impetus in nominal interest Income, we follow recursive formulation approach (Cholesky Decomposition) proposed by Sims (1992). In this approach, ordering of the endogenous variables plays a crucial role as variables appearing later will respond contemporaneously to any change in the variables appearing earlier. As we are more likely to calculate the impact of any change in nominal interest income to nominal GDP, we place nominal interest income before nominal GDP in the representation of the endogenous variables.

- Once the impact and cumulative responses of GDP to shocks in interest income and responses of interest income to its own shock are noted we are in the position to calculate the nominal interest income multipliers defined in the previous sections. We then divide the impact (cumulative) response of GDP to shocks in interest income by the impact (cumulative) response of interest income to its own shock in order to estimate the corresponding impact (cumulative) multipliers.

- As the panel data used in our analysis are in their natural logarithmic form the multipliers calculated above also have the same unit. To convert the multipliers back to their original form we need to divide them by the average value of the ratio of interest income to GDP in the sampling interval used to generate the results.

- After we are done with the impulse response analysis we perform variance decomposition of GDP with respect to interest income. Variance decomposition of GDP under VECM framework allows us to quantify how much of the variance in GDP can be attributed to interest income and how much of it is due to GDP itself.

- On the other hand, if the longitudinal data used in our analysis are not cointegrated then we build an unrestricted VAR model (instead of a VECM) using the variables in their logged first differenced form. Infact, VAR mehtodology has been predominantly used in the empirical estimation of different economic multipliers (see Fatas and Mihov (2001), Blanchard and Perotti (2002), Gonzalez-Garcia et al (2013) for example). Using the footprint of the above literature, we also resort to VAR analysis in order to calculate nominal interest income multiplier. Following Ilzetzki et al (2013), the below-mentioned VAR model is estimated:

$$
A Y_{t}=\sum_{j=1}^{k} C_{j} Y_{t-j}+B u_{t}
$$

where $Y_{t}$ is the vector comprising interest income (expense) and GDP at time period $t, Y_{t-j}, 1 \leq j \leq k$ are lagged terms of the vector of the endogenous variables at time period $t-j, C_{j}, 1 \leq j \leq k$ are the coefficients of the autoregressive terms of $Y_{t-j}, u_{t}$ is the vector of orthogonal, identically distributed shocks in endogenous variables and matrix $B$ is a diagonal matrix. Finally, matrix $A$ allows for the possibility of simultaneous interactions amongst the endogenous variables in our VAR model. In structural VAR analysis, various restrictions are usually imposed on matrix $A$ and more often than not, these restrictions are inspired from the relevant economic theory. In this study, we follow the recursive formulation approach (otherwise known as Cholesky decomposition) proposed by Sims (1992). In Sims' method, the matrix $A$ is assumed to be a lower triangular matrix where the diagonal elements are restrictively set to 1 . Such restriction on matrix $A$ ensures that the covariance matrix of the error vector $u_{t}$ are diagonal. These uncorrelated/orthogonal error terms are referred to as structural errors (see Zivot et al (2003) for more details). Under Sims' approach where $A$ is assumed to be a lower triangular matrix with all ' 1 ' in the diagonal, any endogenous variable appearing beforehand any other endogenous variable in VAR representation is supposed to have a contemporaneous impact on the values of the variable appearing later in the representation and not the vice versa. As we are more interested to capture the cumulative impact of interest income (expense) on GDP in this study, we place interest income before GDP in our VAR model. Such ordering of the endogenous variables implies that interest income (expense) will have a contemporaneous effect on GDP and not the other way around.

- After the VAR model is built, the impulse response analysis and variance decomposition are done in the same way as we do it for VECM. 


\section{Data}

We collect annual time series data of lending rate, domestic credit as percentage of GDP and GDP in current USD from World Bank Open data (World Bank, 2020) during the period 1967-2014 for 04 (four) OECD countries including Australia, Japan, UK and USA. The date range and country choice are determined based upon the availability of the required data series. The country-wise descriptive statistics of the compiled data are furnished in Table: 1 .

Table 1: Descriptive statistics for interest income (figures in USD Billion)

\begin{tabular}{lrrrr}
\hline Country & Australia & Japan & UK & USA \\
\hline \hline Year & $1969-2014$ & $1969-2014$ & $1969-2014$ & $1969-2014$ \\
Mean & 31.34 & 165.03 & 66.00 & 692.19 \\
Median & 20.36 & 138.13 & 28.13 & 587.84 \\
Maximum & 132.20 & 512.76 & 290.04 & 2404.36 \\
Minimum & 0.38 & 7.38 & 1.23 & 42.24 \\
Std. Dev. & 38.63 & 124.83 & 69.57 & 541.28 \\
Skewness & 1.51 & 1.15 & 1.33 & 1.07 \\
Kurtosis & 4.02 & 3.74 & 4.47 & 4.23 \\
& & & & \\
Jarque-Bera & 20.19755 & 11.67336 & 18.45914 & 12.13867 \\
Probability & 0.000041 & 0.002919 & 0.000098 & 0.002313 \\
& & & & \\
Sum & 1504.23 & 7921.38 & 3167.86 & 33225.09 \\
Sum Sq. Dev. & 70127.72 & 732320.80 & 227463.80 & 13770015.00 \\
& & & & \\
Observations & 48 & 48 & 48 & \\
& & & & \\
Correlation with GDP & 0.98 & 0.52 & 0.60 & 0.80 \\
\hline
\end{tabular}

From Table: 1 it is evident that the interest income is highly correlated to the GDP. For Australia, Japan, UK and USA the correlation coefficients are found to be $0.98,0.52,0.60$ and 0.80 respectively.

Moreover, we use median interest rate of government securities to appropriately discount the future responses of GDP and interest income obtained from impulse response analysis under structural panel VAR framework and the interest rate data are collected from IMF data warehouse (IMF (2020)).

We begin our formal analysis by performing panel unit root testing of the compiled data. The annual time series data of interest income and GDP of different countries are stacked together to form a panel data of cross section 04 (four). Five different panel unit root testings have been performed. Tests include Levin-LinChu panel unit root test, Breitung t-statistic test, Im, Pesaran and Shin W-statistic test, ADF-Fisher Chi-square test and PP-Fisher Chi-square test. We use both intercept and trend in the test settings as all of our four cross sectional data contains clearly visible trend and intercept components. Before we perform panel unit root testing on our longitudinal data we first convert them into their natural logarithmic form in order to remove heteroskedasticity. The results of panel unit root testing are presented in Table: 2. From Table: 2 it is evident that both interest income and GDP are integrated of order 01 (one) as anticipated. 


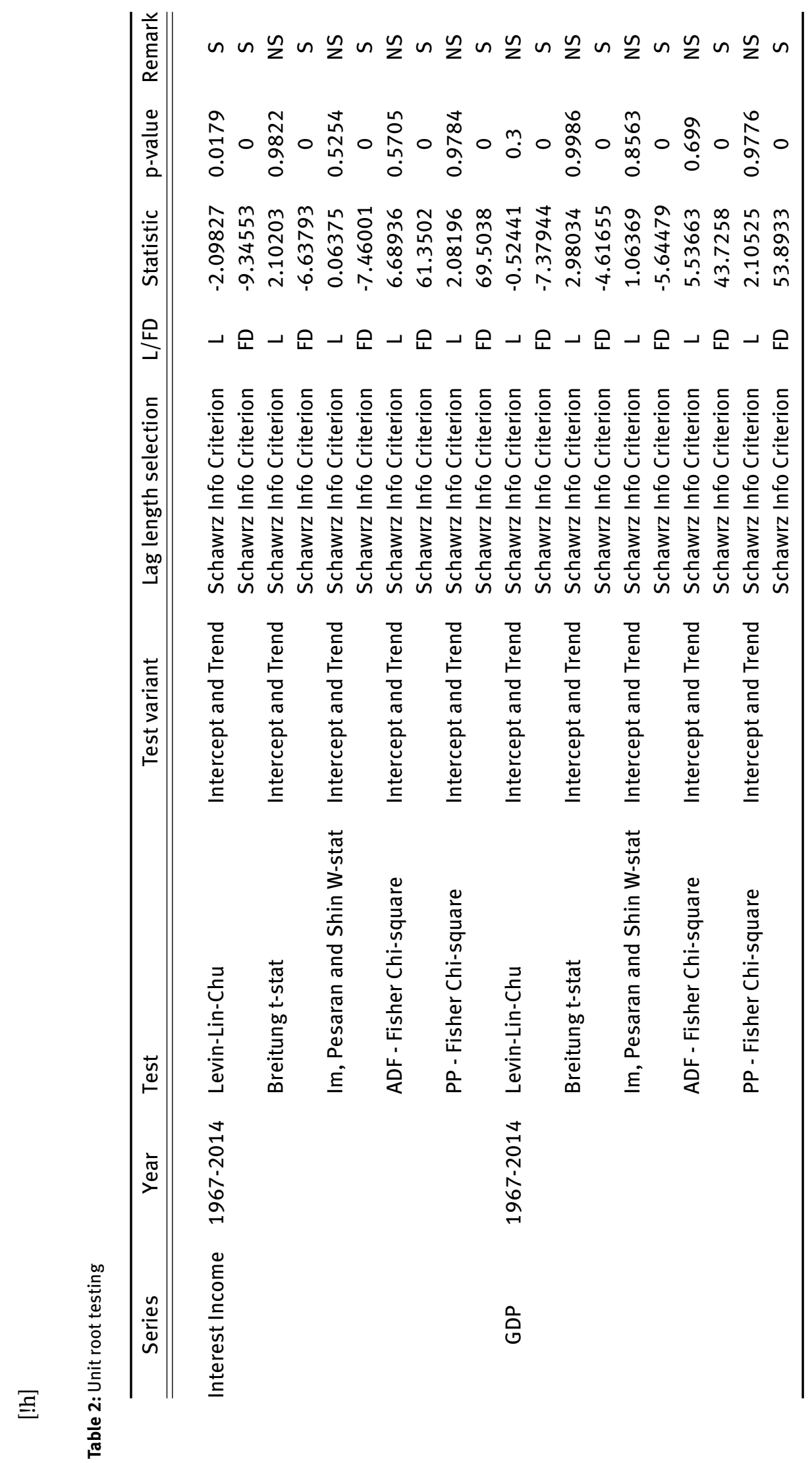




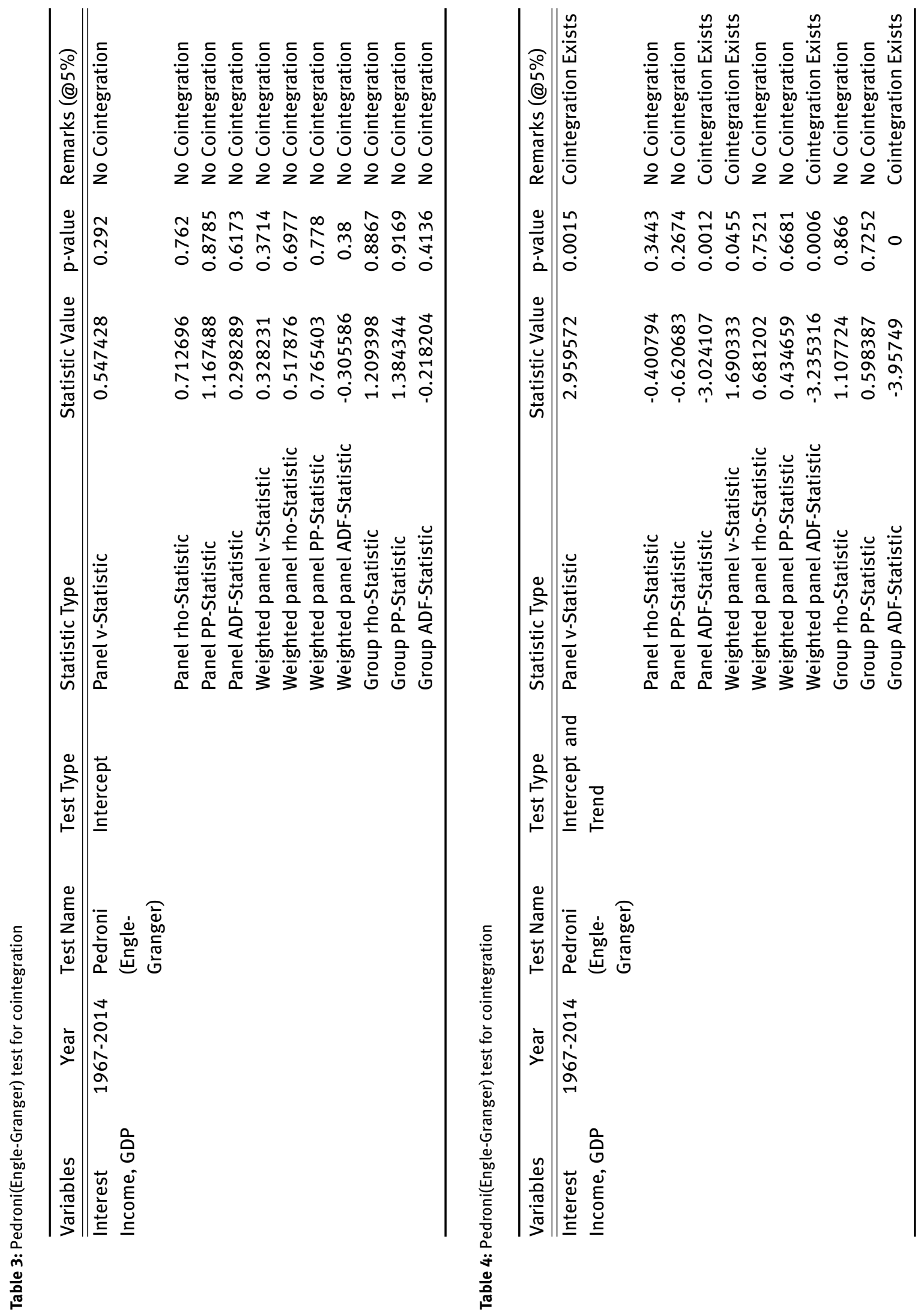



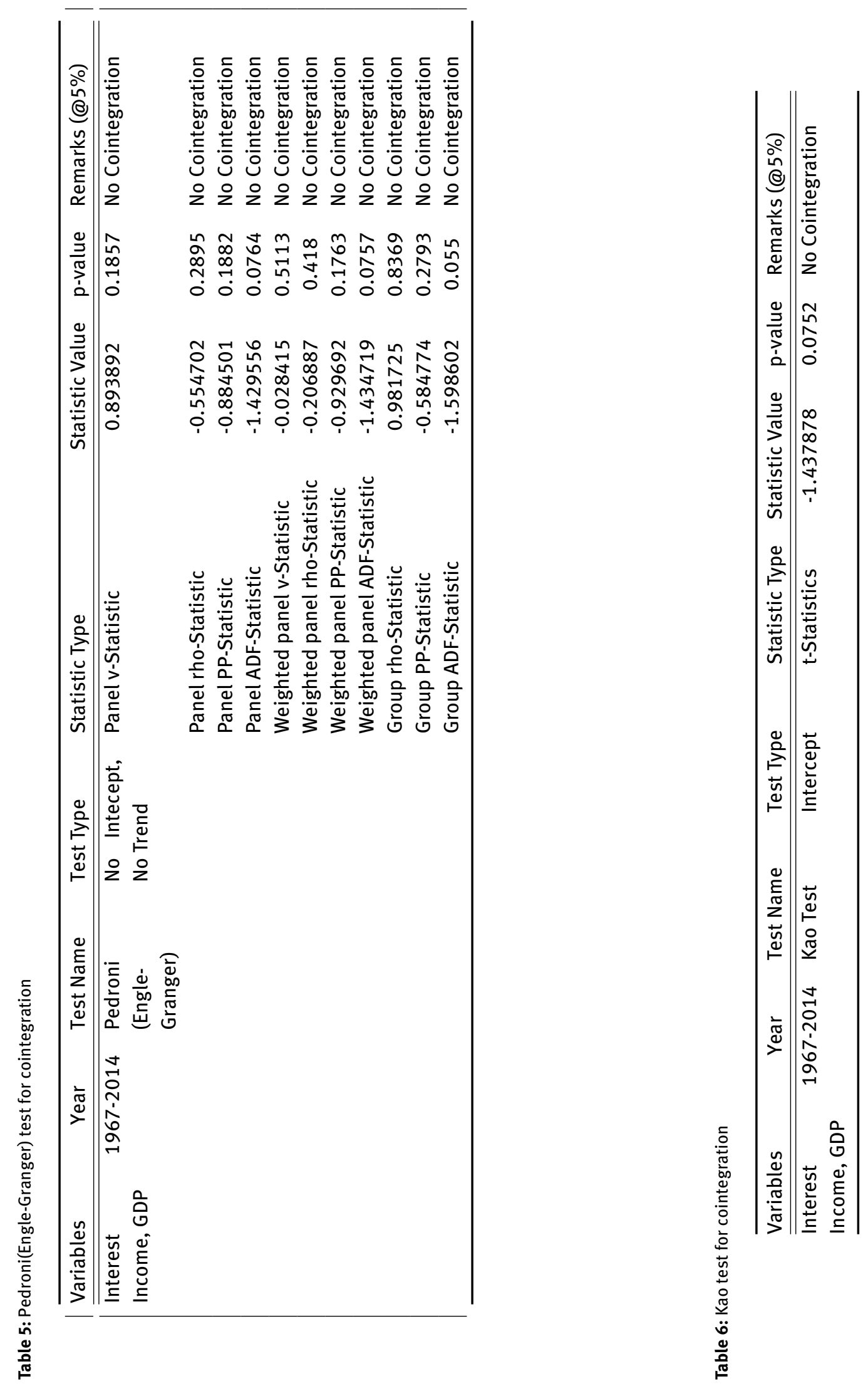


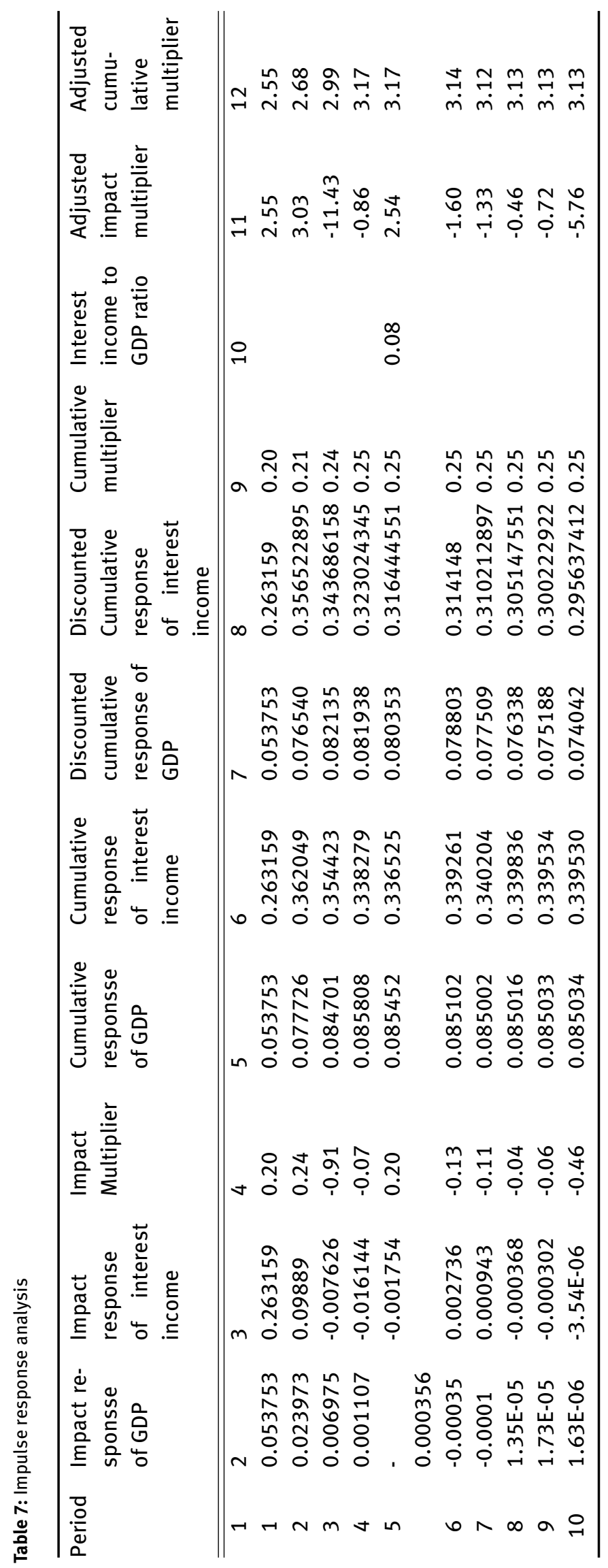




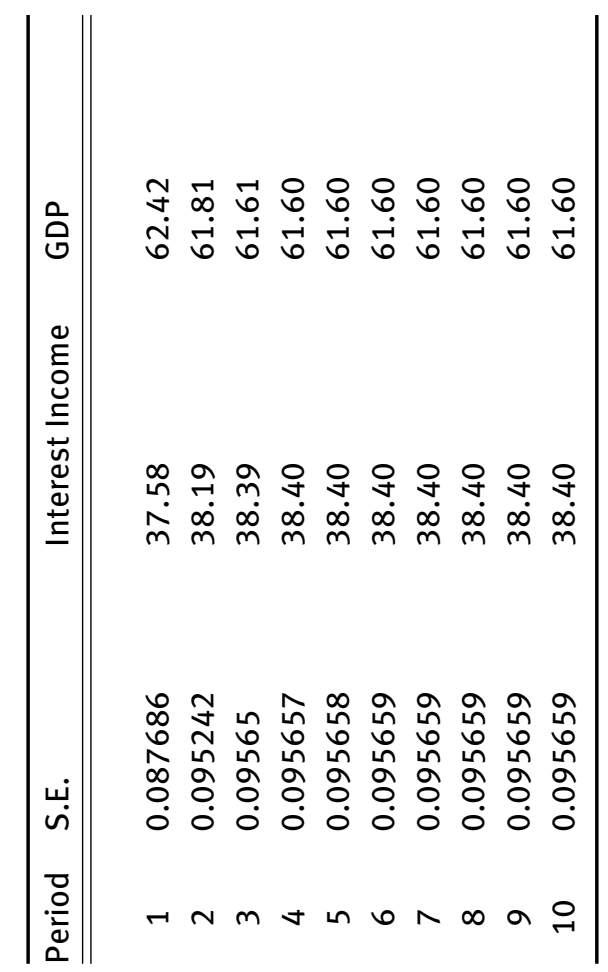

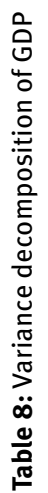


As both the data series are integrated of order 01 (one) we can check whether there exists any cointegrating relationship amongst the two series. Two different cointegration tests are performed: Pedroni (EngleGranger type) cointegration test and Kao test for cointegration. Pedroni (Engle-Granger) test reports the presence/absence of cointegration using 11 (eleven) different statistics. Each statistics either suggest or reject cointegration amongst the series. Moreover, Pedroni test of cointegration comes up with three distinct variants: Individual intercept, individual intercept and individual trend and finally no intercept and no trend. All three variants are tested. Results of Pedroni (Engle-Granger based) cointegration test with individual intercept only are presented in Table: 3. From Table: 3 it is evident that all the 11 (eleven) test statistics reject the presence of cointegration between interest income and GDP. In the next step we perform Pedroni test of cointegration using individual intercept and individual trend and in this case 05 (five) out of 11 (eleven) test statistics suggest the presence of cointegration while the rest 06 (six) reject it (see Table: 4 for reference). As we rely on the majority the null hypothesis of no cointegration can not be rejected in this case also. Finally, Pedroni test is performed using no intercept and no trend and the results are presented in Table: 5 . From Table: 5 it can be seen that all the test statistics soundly reject the presence of cointegration between interest income and output. So, all the three variants of Pedroni test reject the presence of cointegration amongst the variables.

In the next step we perform Kao test of cointegration on the longitudinal data of interest income and output and results are presented in Table: 6 . For the Kao test the t-Statistic value is found to be -1.437878 and the corresponding probability value is 0.0752 . So @ $5 \%$ level we can not reject the null hypothesis of no cointegration. So, the results of both the Pedroni and Kao test of cointegration coincide and we reject the presence of cointegration between interest income and output.

As the series are not cointegrated we discard the idea of performing impulse response analysis on VECM framework. Rather we build an unrestricted VAR model with the appropriate number lags for each of the endogenous variables in logarithmic first differenced form and perform impulse response analysis on this. The variables are converted into first differenced form as the VAR methodology requires the series under consideration to be stationary and the log-transformation is performed to remove heteroskedasticity from the data. The next step to construct an appropriate structural panel VAR model is to determine the appropriate lag length for the endogenous variables. Although not reported here all the information criteria suggest 02 (two) lags for each of the endogenous variables. Moreover, the VAR model with 02 (two) lags is found to be dynamically stable.

Response to Cholesky One S.D. Innovations - 2 S.E.

Response of $D\left(L N \_G D P\right)$ to $D\left(L N \_I I\right)$

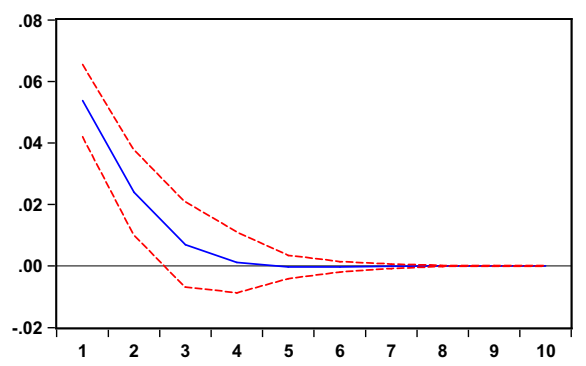

Figure 1: Impact response of GDP to shocks in interest income

In our VAR representation interest income precedes GDP as we are more interested to capture the impact of interest income on output. Once the VAR model is so specified we provide one standard deviation Cholesky shock in interest income and note down both the impact and cumulative response of GDP as a result. Impact and cumulative responses of GDP to shocks in interest income are presented in Figs: 1 and 2 respectively. From Fig: 1 it is evident that GDP responds positively to any positive shock in interest income although its response eventually diminishes to zero. The diminishing return is mainly due to the fact that we use the 


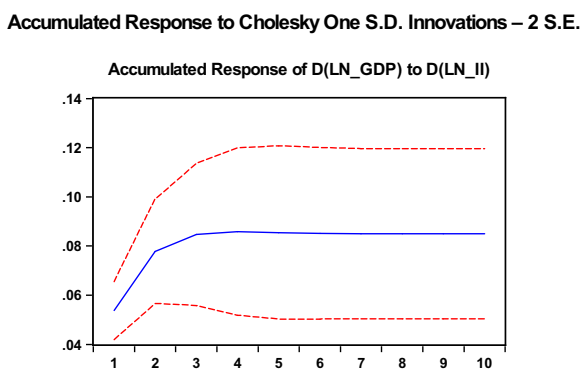

Figure 2: Cumulative response of GDP to shocks in interest income

variables in their stationary (logarithmic first-differenced) form. So, any exogenous shock is absorbed after some initial jittering and the system eventually returns to its original equilibrium level. One interesting fact here is that the GDP responds positively to any change in interest income or equivalently in total interest expense. The positive correlation between interest income (or total interest expense) is further elaborated into the discussion section of this article.

Moreover, the impact and cumulative responses of interest income to its own shock are also noted and they are graphically represented in Figs: 3 and 4 respectively. Once the impact and cumulative responses of GDP and interest income to shocks in interest income are noted we are now in the position to calculate the corresponding interest income multiplier values. To estimate the impact (cumulative) multipliers we divide the impact response of GDP to shocks in interest income by the impact response of interest income to its own shock. As we use data in their natural logarithmic form what we obtain here is simply the elasticity of output with respect to interest income. So, to get the multiplier values we need to divide the values obtained thus far by the average value of interest income to GDP ratio in the sample (See Gonzalez-Garcia et al. (2013) for example).

Response to Cholesky One S.D. Innovations - 2 S.E.

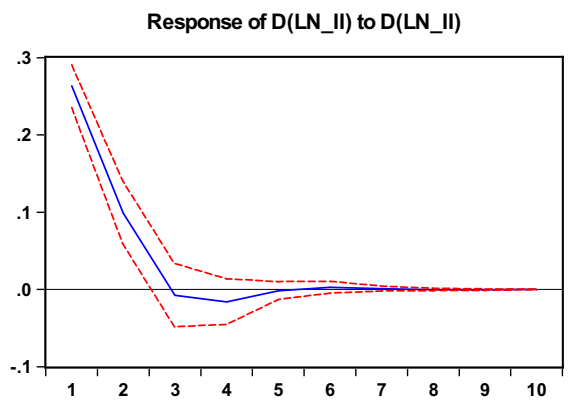

Figure 3: Impact response of interest income to its own shock

The impact and cumulative multipliers obtained in the above manner are reported into column-11 and column-12 of Table: 7 . From column-11 of Table: 7 it can be seen that the impact multipliers vary rather unusually within the range of -11.53 to 3.03 . The large negative values of the impact multipliers are rather insignificant in its overall impact as it corresponds to very little changes in output. However, this very little change in output is paired with even smaller changes in interest income and hence comes the surprisingly large but insignificant impact multiplier values. These negative values of impact multipliers are insignificant as their impact on output are easily offsetted by the earlier much larger positive co-movements. These facts are clearly captured by the cumulative multipliers and as can be seen from column-12 of Table: 7 . It is evident 


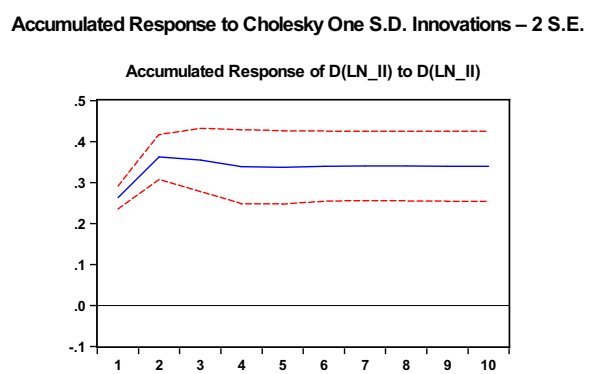

Figure 4: Cumulative response of interest income to its own shock

from column-12 of Table: 7 that the cumulative multipliers do not vary a lot. Rather they show consistently positive values varying within a relatively short interval of 2.55 to 3.17 .

In the next step we analyze the variance decomposition of GDP with respect to interest income and the results are depicted in Table: 8. From Table: 8 it is evident that during period 01 (one) $37.58 \%$ of the variance in GDP is attributed to interest income. The stake of interest income in the variance in GDP remains relatively stable over the forecasting horizon and reaches the value of $38.40 \%$ during period 10 .

In this study, we have defined and calculated interest income multiplier which embodies the change in national output in response to any shock in interest income. To the best of our knowledge, no previous study relating to interest income/expense and GDP has been conducted in this direction, i.e., the concept of interest income multiplier was totally missing in the theoretical/empirical literature thus far and we have brought this concept to light through this study. As anticipated from the analysis presented in this text, the cumulative interest income multipliers are found to be positive consistently throughout the periods under investigation varying in between 2.55 to 3.17. Consistently positive estimate of the cumulative multipliers reinforces our theoretical reasoning presented in this article.

\section{Discussion}

Interest rate is said to have manifold impact on output. To name a few:

- Substitution Effect: Higher interest rate is said to reduce public consumption through substitution effect. When interest rate rises households tend to prefer future consumption to the present one. It is because present consumption seems to be costlier than its future counter part and people prefer savings over consumption.

- Income Effect: Higher interest rate also means households get more return on their savings. As the interest income increases, so does the total disposable income of the households. So, households tend to spend more on consumption. Thus income effect partly compensates for the negative impact of substitution effect of higher interest rate on public consumption.

- Impact on investment: Level of investment in the economy is sensitive to changes in interest rate. When interest rate reduces it attracts more investment as the projected return of investment becomes more and more compatible with the interest rate. As investment is part of the GDP, GDP also increases. On the contrary, when interest rate increases investments are distracted away.

Although the role of interest rate on output has been thoroughly investigated in the literature, role of interest expense on output has been left unattended and here we argue that interest expense can be substantially different from interest rate alone. An increase (decrease) in interest rate may or may not lead to an increase (decrease) in total interest expense. To look more closely into the matter, let us recall the definition of interest expense.

$$
I E=l \times L
$$


From the above equation we can see that if the total volume of credit remains unchanged, an increase in interest rate may bring about a proportional increase in interest expense. However, the total volume of credit is susceptible to interest rate and responds contemporaneously to any change in it. So, when interest rate increases the total volume of credit tends to decrease. Apparently, what happens to interest expense (which is simply the product of interest rate and volume of credit) in response to an increase in interest rate becomes unclear as one of its parameters namely, interest rate, increases while the other one, namely, volume of credit, decreases. Infact, change in interest expense in response to change in interest rate will depend upon the elasticity of the credit portfolio with respect to lending rate. To begin a formal analysis, let us assume that a $p \%$ point increase in interest rate will shrink the credit portfolio by $q \%$. If the initial interest expense is given by $l \times L$ then new interest expense will be given by the following:

$$
(1+p) \times l \times(1-q) \times L=(1+p) \times(1-q) \times l \times L
$$

It is evident from the above equation that if $(1+p) \times(1-q)>1$ then interest expense will increase in response to $p \%$ point change in interest rate. Solving for $q$ yields the following:

$$
q<\frac{p}{1+p}
$$

Hence, if we want interest expense to increase after $p \%$ point increase in lending rate then the elasticity of credit portfolio with respect to interest rate must be given by the following construct:

$$
e=\frac{q}{p}<\frac{1}{1+p}
$$

If we want interest expense to reduce after there is $p \%$ point increase in lending rate then elasticity of credit portfolio with respect to interest rate must satisfy the following inequality:

$$
e=\frac{q}{p}>\frac{1}{1+p}
$$

Finally, If we want interest expense to remain unchanged after a $p \%$ point increase in lending rate is introduced then elasticity of credit portfolio with respect to interest rate must satisfy the following equality:

$$
e=\frac{q}{p}=\frac{1}{1+p}
$$

Present literatures relating to interest rate and output are quite inconclusive while some studies have identified significant negative inter-relation between interest rate and output whereas others rejected it in favor of monetary neutrality. Here, we argue that the impact of interest rate on output can be significantly different than that of interest expense. When interest rate rises due to monetary contraction, interest expense at the national level may rise or fall depending upon the responsiveness of the credit portfolio to changes in interest rate. If the credit portfolio responds significantly to the rise in interest rate and shrinks accordingly, then the total interest expense will decline resulting into a dip in national output. However, on the contrary to the existing literature, if the credit portfolio does not adjust to the rising interest rate, then the total interest expense will rise as well resulting into further expansion in national output. The opposite holds true as well for a monetary expansion followed by a lowered interest rate. Thus, in this study, we have provided a new line of thinking which may provide explanation of why monetary contraction may fail to brace a galloping GDP and also why monetary expansion may not rejuvenate national output as anticipated by the existing monetary theory.

\section{Conclusion}

Although, the existing literature has thoroughly investigated the relationship between interest rate and GDP, the relationship between interest expense and GDP has been left unattended so long. Interest expense has 
been thus far considered as a monetary phenomenon affecting the general price level only with little to no real significance and its relation to GDP through interest income channel has been mostly overlooked. Here, we unveil the interest income channel which enables us to view the dynamics between interest expense and GDP in greater detail which is substantially different from that of interest rate and GDP.

\title{
List of Abbreviations
}

\author{
GS: Gross Savings \\ IE: Interest Expense \\ IM: Impact Multiplier \\ CM: Cumulative Multiplier
}

Acknowledgement: Not applicable.

Competing interests: There is no relevant competing interest exists.

Funding: No funding is received to accomplish this work

Author Role: This is a single author paper. The author is responsible for idea generation, literature review, analysis, methodology, data collection, empirical analysis and discussion.

Data Availability: All the data used in the analysis are publicly available in World Bank Open Data accessible through: https://data.worldbank.org/.

Disclaimer: The opinions expressed in this article are those of the author and do not necessarily reflect the official policy or position of any agency, organization, employer or company.

\section{References}

Barth, M. and V. Ramey, 2001, The Cost Channel of Monetary Transmission, NBER Macroeconomics Annual 2001, Cambridge, MIT Press, pp. 199-240.

Bernanke, B., Gertler, M., 1995, Inside the black box: The credit channel of monetary policy transmission, Journal of Economic Perspectives 9(4):27-48.

Bernanke, Ben, Mark Gertler, and Simon Gilchrist, 1999, The Financial Accelerator in a Quantitative Business Cycle Framework, Handbook of Macroeconomics, John Taylor and Michael Woodford editors.

Blanchard, Olivier and Roberto Perotti, 2002, An Empirical Characterization of the Dynamic Effects of Changes in Government Spending and Taxes on Output, MIT Press, The Quarterly Journal of Economics, Vol. 117(4): 1329-1368.

Blinder, A., 1985, Credit rationing and effective supply failure, NBER working paper series.

Christiano, Lawrence, Roberto Motto and Massimo Rostagno, 2005, The Great Depression and the Friedman-Schwartz Hypothesis, Journal of Money Credit and Banking.

Coibion, O. (2011). Are the effects of monetary policy shocks big or small? NBER Working Paper, 17034. Cambridge, M.A.

Davoodi, M. H. R., Dixit, M. S., \& Pinter, G. (2013). Monetary transmission mechanism in the East African Community: An empirical investigation. International Monetary Fund.

Dedola, L., Lippi, F., 2005, The monetary transmission mechanism: evidence from the industries of five OECD countries, European Economic Review 49, 1543-1569.

Fatas, Antonio and Ilian Mihov, 2001, The Effects of Fiscal Policy on Consumption and Employment: Theory and Evidence, Centre for Economic Policy Research, CEPR Discussion Papers, No. 2760, April.

Gertler, M and Karadi, P, 2011, A Model of Unconventional Monetary Policy, Journal of Monetary Economics, Volume 58, Issue 1, January 2011, Pages 17-34.

Gaiotti, E., Secchi, A., 2006, Is there a cost channel of monetary policy transmission? An investigation into the pricing behaviour of 2,000 firms, Journal of Money, Credit, and Banking, v. 38, 8, pp. 2013-2038 . 
Gonzalez-Garcia, Jesus, Lemus,Antonio and Mrkaic, Mico, 2013, Fiscal Multipliers in the ECCU, IMF Working Paper Series.

Havi, E. D. K., \& Enu, P. (2014). The effect of fiscal policy and monetary policy on Ghana's economic growth: which policy is more potent. International Journal of Empirical Finance, 3(2), 61-75.

Hicks, J., 1979, Is Interest the Price of a Factor of Production? J. M. Rizzo (ed.), Time, Uncertainty and Disequilibrium.

Ilzetzki, Ethan, Mendoza, Enrique G. and Vegh, Carlos A., 2013. How big (small?) are fiscal multipliers?, Journal of Monetary Economics, Elsevier, vol. 60(2), pages 239-254.

IMF, 2020, IMF Data Warehouse, Viewed on May 5, 2020. URL: https://data.imf.org/regular.aspx?key=61545867

Kamaan, C. K., \& Nyamongo, E. M. (2014). The effect of monetary policy on economic growth in Kenya. International Journal of Business and Commerce, 3(8), 11-24.

Kareem, R. O., Afolabi, A. J., Raheem, K. A., \& Bashir, N. O. (2013). Analysis of fiscal and monetary policies on economic growth: Evidence from Nigerian democracy. Current Research Journal of Economic Theory, 5(1), 11-19.

Lashkary, M., \& Kashani, B. H. (2011). The impact of monetary variables on economic growth in Iran: A Monetarists' Approach. World Applied Sciences Journal, 15(3), 449-456.

Meh, Cesaire A. and Moran, Kevin, 2010, The role of bank's capital in the propagation of shocks, Journal of Economic Dynamics and Control 34(3): 555-576.

Milani, F., \& Treadwell, J. (2012). The effects of monetary policy "news" and "surprises". Journal of money, credit and banking, 44(8), 1667-1692.

Montiel, P., Adam, C. S., Mbowe, W., \& O'Connell, S. (2012). Financial Architecture and the Monetary Transmission Mechanism in Tanzania.

Onyeiwu, C. (2012). Monetary policy and economic growth of Nigeria. Journal of Economics and Sustainable development, 3(7), 62-70.

Rabanal, P., 2003, The cost channel of monetary policy: Further evidence for the united states and the euro area, Working Paper 03-7149, IMF.

Seelig, A. S.,1974, September, Rising Interest Rate and Cost Push Inflation, Vol. 29, No. 4, pp. 1049-1061 .

Sims, Christopher A., 1980, Macroeconomics and Reality, Econometrica, Vol. 48(1): 1-48.

Sims, C., 1992, Interpreting the macroeconomic time series facts: The effects of monetary policy, European Economic Review 36(5):975-1000.

Smets, Frank and Wouters, Rafael, 2007, Shocks and Frictions in U.S. Business Cycles: A Bayesian DSGE Approach, American Economic Review.

Tillmann, P., 2006, Does the cost channel of monetary transmission explain inflation dynamics? Mimeo, University of Bonn.

Twinoburyo, E. N., \& Odhiambo, N. M. (2018). Monetary policy and economic growth: A review of international literature. Journal of Central Banking Theory and Practice, 7(2), 123-137.

Vinayagathasan, T. (2013). Monetary policy and the real economy: A Structural VAR Approach for Sri Lanka. National Graduate Institute for Policy Studies, 13(13), 1-31.

World Bank, 2020, World Bank Open Data, viewed on May 5, 2020, URL: https://data.worldbank.org/

Zivot E., Wang J. (2003), Vector Autoregressive Models for Multivariate Time Series. In: Modeling Financial Time Series with SPlus. Springer, New York, NY. 